\title{
ANALES
}

de la

\section{Facultad de Medicina de Lima}

TOMO III - AÑO 1919

\section{Sobre un caso de micosis cutanea}

\author{
POR EL DR. RAMON E. RIBEYRO \\ Profesor de Parasitologia en la Facultad de Medicina
}

A fines de 1905, mi amigo el Dr. M. Aljovín, me indico que examinara un enfermo que presentaba desde hacía mucho tiempo, una erupción pustulosa en los miembros superiores é inferiores. Como resultado de los exámenes que hice, encontré un hongo no descrito, que según toda probabilidad era el agente patógeno de la lesión.

\section{HISTORIA CLINICA.}

El Sr. M. hacia 2 años que padecía de una afección muy rebelde de la piel; ésta consistía en la aparición de pequeñas pápulas rojizas, que se convertían después de 263 días, en pustulitas acuminadas, amarillentas y con eminencia central un poco mas oscura; su contenido era seroso, ligeramente turbio. Estas vesiculitas tenian I $\delta 2$ milímetros de diámetro y estaban implantadas sobre una pápula rojiza, ligeramente elevada. Las pústulas provocaban desde su aparición, un escozor muy vivo. El rascado rompía la pústula y dejaba en su lugar una costra oscura, semejante á la que se observa después de romper una pequeña pústula de varicela; la pús.tula rota, provocaba igualmente vivo escozor por varios días, desapareciendo después, sin dejar cicatriz. El paciente había observado que la regresión de las pústulas era muy rápida, cuando se aplicaba tintura de iodo. 
La erupción aunque generalizada á los brazos, piernas y á la cara anterior del torax, era relativamente discreta; en el momento del examen se podían contar 30 ó 40 pústulas en diverso grado de desarrollo.

El Sr. M. había contraído la afección en su hacienda, situada en una quebrada estrecha y calurosa de la provincia de Cotabambas (Departamento de Apurímac).

La primera impresión que producía esta dermatosis era la de una afección de orígen artrítico; pero había que eliminar esta creencia, por el fracaso absoluto de una medicación apropiada y fielmente seguida.

Con el objeto de orientarnos sobre el orígen de la afección, hicimos los siguientes examenes:

a) Reacción de Wassermann. Resultado: Negativo.

b) Examen ultramicroscópico del contenido de la pústula. Nada digno de notarse.

c) Examen de frottis coloreados al Giemsa en los que podían observarse: Leucocitos escasos, con inclusiones teñidas en rojo rosado cocus (?), elementos pequeños de forma de cocobacilos, de 2 á.3 micra de largo por 1 micron de ancho.

En el primer examen no dimos importancia á estos últimos elementos que consideramos como gérmenes de contaminación secundaria.

d) Cultivos en gelosa ordinaria. Al octavo día, desarrollo de colonias pequeñas, cremosas.

El examen de estas colonias nos muestra filamentos micelianos muy finos, ramificados.

No hay esporas, ni organos de fructificación. En los cultivos no se encuentran gérmenes de ninguna otra clase.

A los diez dias, en vista de este resultado, y con el objeto de confirmar nuestra investigación primera, volvimos á examinar al enfermo. El resultado fué idéntico, es decir, cocus y coco-bacilos en los frottis; cultivos puros de un hongo en la gelosa ordinaria.

Era pues evidente, que nos encontrábamos en presencia de una afección micósica.

Se le había recomendado al enfermo que se dirigiera a Ica, á tomar, durante cierto tiempo, las aguas de Huacachina. El enfermo partió para ese lugar algunos días después, y hube por lo tanto de interrumpir el estudio de la marcha de la enfermedad

Pocos datos mas puedo agregar sobre el enfermo; debo solamente indicar que el Sr. M. me dijo que la enfermedad la habia 
contraído en su hacienda en la que había observado á otras personas atacadas de idéntica dolencia.

Posteriormente no he teñido noticia de él.

\section{DESCRIPCION DEL HONGO.} cultivos.

El hongo se puede observar en la vida parasitaria y en los

En la vida parasitaria se presenta bajo la forma de elementos redondeados, muy pequeños que tienen el aspecto de coccus 6 bien ligeramente alargados, semejando coco-bacilos, de 162 micra de largo por 1 micron de ancho, rectos $\delta$ ligeramente encorvados. Estos elementos se encuentran libres $\sigma$ bien englobados por leucocitos. Se dejan colorear bien por los colorantes básicos. Con el Giemsa toman un color rojo-rosado. No hemos podido observar las relaciones del hongo con los elementos histológicos de la piel.

En los cultivos se presentan bajo dos formas: una forma filamentosa y una forma esporular.

La forma filamentosa se observa en los cultivos jovenes, (de 8, 10 - 20 dias). Se encuentra una malla muy apretada de filamentos micelianos finos, ramificados. Estos filamentos tienen $\frac{1}{2} \mathrm{~mm}$. de diámetro y un largo considerable. Toman bien los colores de anilina. El tubo miceliano nos ha parecido continuo, es decir, sin tabiques de separación. La forma esporular, se observa en los cultivos de 20 días ó mas. Todos los elementos micelianos se trasforman en esporas pequeñas de $1 \mathrm{~mm}$. de diámetro. Cuando se observa un cultivo de 20 días, es frecuente observar al lado de formas micelianasfilamentosas, y de esporas, formas en esrrepto, indicio de una próxima dislocación del tubo mic eliano.

Cultivos.

El hongo crece bien en los diversos medios generalmente empleados, siendo de notarse que se desarrolla mejor en los medios simples que en los azucarados. A los 8 días da colonias ligeramente elevadas, de color cremoso, de aspecto graso. A los 15 o 20 días cuando comienza la desecación del medio, aparecen puntos blancos sobre el cultivo y poco á poco todas las colonias quedan convertidas en una zona blanca, opaca, de aspecto pulverulento. El examen del cultivo hace observar durante el pri- 
mer período filamentos micelianos y durante el segundo, solo esporas.

Caldo ordinario.--Se desarrolla facilmente. Al cabo de 5 ó 6 dias se ven pequeñas motitas blancas, con filamentos radiados, flotando en la superficie y formando un velo poco apretado. Por agitación parte del velo cae al fondo.

Medio de Sabouraud. --El hongo crece mal en este medio. En muchos casos no se desarrolla.

Gelaíina.--Sembrando en picadura, se desarrolla debilmente en el trazo de la picadura y abundantemente en la superficie formando un boton cremoso que después se vuelve blanco. pulverulento. No la liquida. Todos los cultivos despiden un olor suigeneris de mor.o. muy perceptible.

INOCULACIONES EXPERIMENTALES.

En el conejo la inyección de esporas en el peritoneo y en el sistema venoso no dió resultado perceptible.

La fricción de un cultivo sobre la piel del dorso, recientemente af eitado, no.produ jo ningún fenómeno digno de anotarse.

$E_{n}$ inyeccion subcutánea, se desatrolla al $3^{\circ}$ día un nodulo que puede alcanzar al tamaño de una arbeja. En el interior se encuentran una cavidad que contiene un líquido turbio con leucocitos, mono y polinucleares y gran cantidad de elementos micósicos, libres ó incluídos en los leucocitos El nódulo desaparece expontaneamente á los 15 ó 20 días.

En el conejillo de Indias (cobayo) la inoculación de esporas, dá exactamente los mismos resulta dos que en el cone jo.

Clasificacion.

Es indudable que el hongo que acabamos de describir, debe entrar en el grupo heterogeneo y mal definido de los Hyphomicetos ú Hongos imperfectos.

VUILlEMIN (1) ha propuesto una división de este orden, basado en caracteres morfológicos faciles de observar.

Este autor divide los Hyphomicetos en 3 grupos:

1) Conidiosporados. en los que coloca á los hongos que presentan conidias bien diferenciadas desde su orígen.

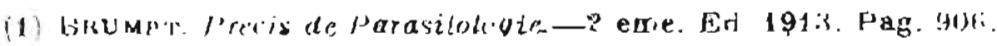




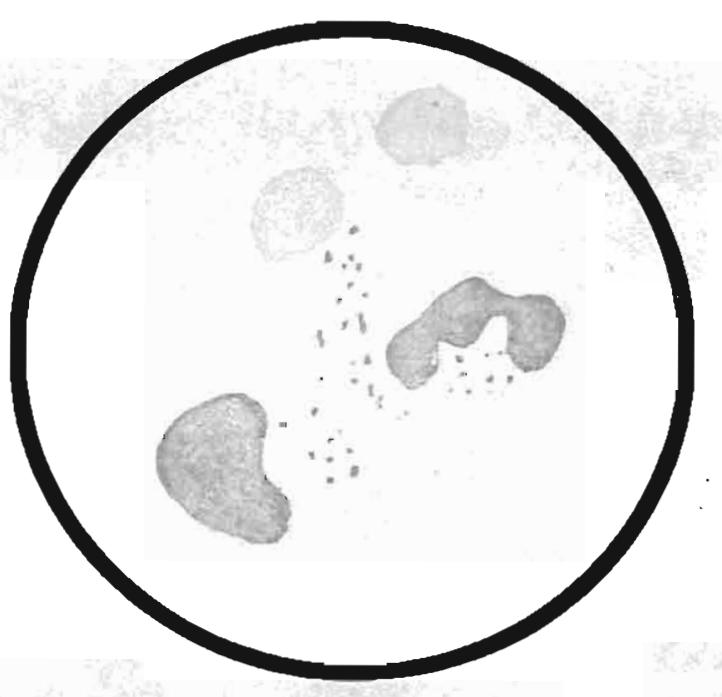

El hongo en la vida parasitaria Frottis

Giemsa. Dibujo Cam. Cl. Abbe. Obj. Imm. Ap. 2 Oc. 6

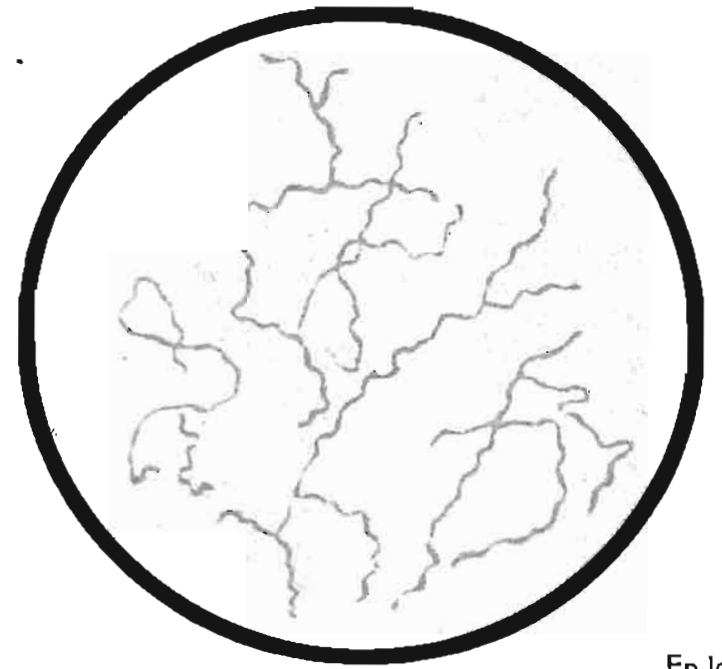

A los 10 dias
En los cultivos

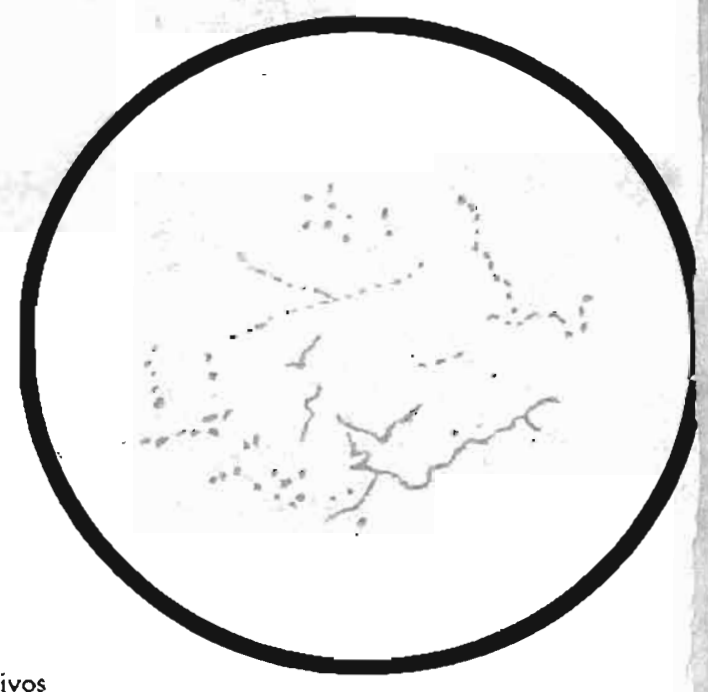

A los 30 dias 
2) Hemisporados, en los que desde su orígen, hay igualmente conidias, pero menos diferenciadas que en el grupo anterior y

3) Tallosporados, en los que la reproducción se hace por tallos. poras las que se generan por división del tallus sin ninguna diferenciación original. Este grupo Vuillemin lo subdivide en dos subgrupos. a) Blastoporados, que se reproducen por gemmación y b) Artrosporados, en los que las esporas se forman por la desar. ticulación del tallus sin diferenciación particular.

El hongo que hemos descrito debe incluirse en esta última categoría. Nos abstenemos por el momento de denominarlo por temor de que pueda caer en sinonimia con un hongo ya descrito y también por la frecuente imprecision que tienen los géneros del grupo de los Hiphomicetos.

Se hace actualmente un estudio mas completo de sus caracteres biológicos, el que nos permitirá conocer algunas de sus particularidades; solo entonces podremos asignarle un sitio mas preciso en la clasificación. 